\title{
Benefits of Online Doctor Consultation During the Pandemic
}

\author{
Madhavi Madhukar Narayane', Pallavi Nimkar ${ }^{2}$, Ninad Nagrale ${ }^{3}$ and Ragini Patil ${ }^{4}$ \\ ${ }^{1}$ Clinical Instructor / Tutor-Medical Surgical Nursing, Datta Meghe \\ College of Nursing, Nagpur, Maharashtra, 441110 India \\ ${ }^{2}$ Clinical Instructor / Tutor-Community health Nursing, Datta Meghe \\ College of Nursing, Nagpur, Maharashtra, 441110 India \\ ${ }^{3}$ Department. of Forensic Medicine Datta Meghe Medical College, \\ Shalinitai Meghe Hospital and Research Centre, Nagpur \\ ${ }^{4}$ Department. of Psychiatry Jawaharlal Nehru Medical College, Datta Meghe \\ Institute of Medical Sciences Sawangi (Meghe), Wardha \\ Corresponding author email: madhavinarayane22@gmail.com
}

\begin{abstract}
Online video consultations between doctors and patient are acceptable and is becoming popular keeping the current pandemic scenario in mind. Online consultation has helped in replacing face to face consultations. Thus it mostly help patients (who don't have to travel and wait in a queue for their turn) and the consultants (making them more cost effective). Irrespective of the location and place, patients get a professional doctor advice staying at his home. A bedridden person don't have to regularly visit hospital for checkup and can get an online consultation from the comfort of his place. At places where Doctors is not reachable or available ,online doctor consultation seems to be helpful there. The only requirement is the internet and device by which they can do remote video consultation with the doctor. In the online consultation privacy plays a key role. Privacy is one of the main advantage of online doctor consultation. Apart from the consultation the records of the patients can be maintained digitally. While consulting online, people can upload there treatment sheet, medical reports and test report. So keeping the current pandemic situation in mind, online doctor consultation seem to be helpful for people in getting there health report regularly from the professional doctors online.
\end{abstract}

KEY WORDS: ONLINE DOCTOR, ONLINE CONSULTATION, ONLINE VIDEO CONSULTATION, REMOTE CHECKUP, DIGITAL RECORDS, PROFESSIONAL DOCTOR.

\section{INTRODUCTION}

In 2015, our Honorable Prime Minister Narendra Modi announced the concept of Digital India delivering services in the finger tips. Five years down the line, India has witnessed major revolution in digital world in many sectors of services (Kaitlin, 2021). In medical field too,

Biosc Biotech Res Comm P-ISSN: 0974-6455 E-ISSN: 2321-4007

\section{crossef}

Identifiers and Pagination

Year: 2021 Vol: 14 No (6) Special Issue

Pages: 53-56

This is an open access article under Creative

Commons License Attribn 4.0 Intl (CC-BY).

DOI: $h t t p: / / d x . d o i . o r g / 10.21786 / b b r c / 14.6 .13$ digitalization has been witnessed where doctors have started providing online consultation. Online doctor consultation has in one way or other has been seen as a boon to all the people of the country. Considering the current pandemic situation due to COVID-19 disease, it has brought a huge transformation in the health sector and resulted in changing the lives of many people. A online doctor appointment using video call on your phone, tablet or desktop is just like using Skype for a business meeting - a more convenient alternative to in-person meeting.

Online doctor consultation is a great option for followup consultation, patients who are chronically ill and for a regular health consultation (Amrita, 2017). Whatever problem you might be having regarding to your health

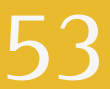


or anything which is not allowing to keep you 100\% fine, seeing a doctor (online or offline) could help you get rid of it (Sawarkar, 2020).

Figure 1: Online Consultation

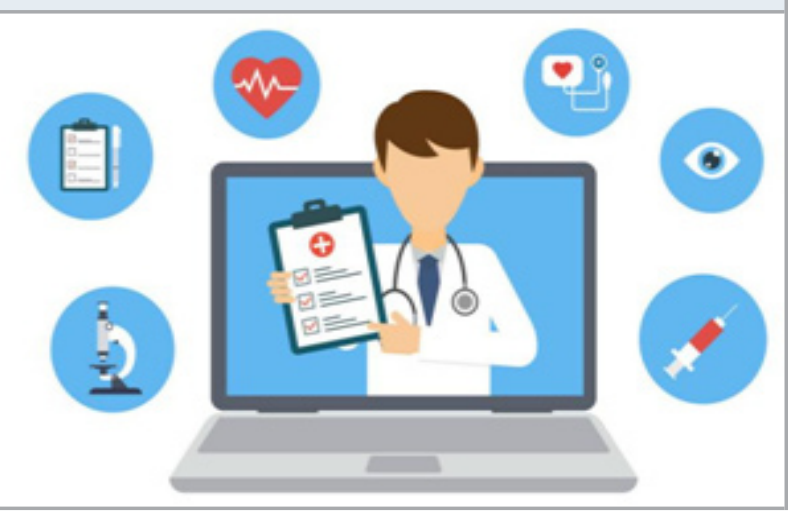

Benefits of online doctor consultation

- Get instant help from doctor

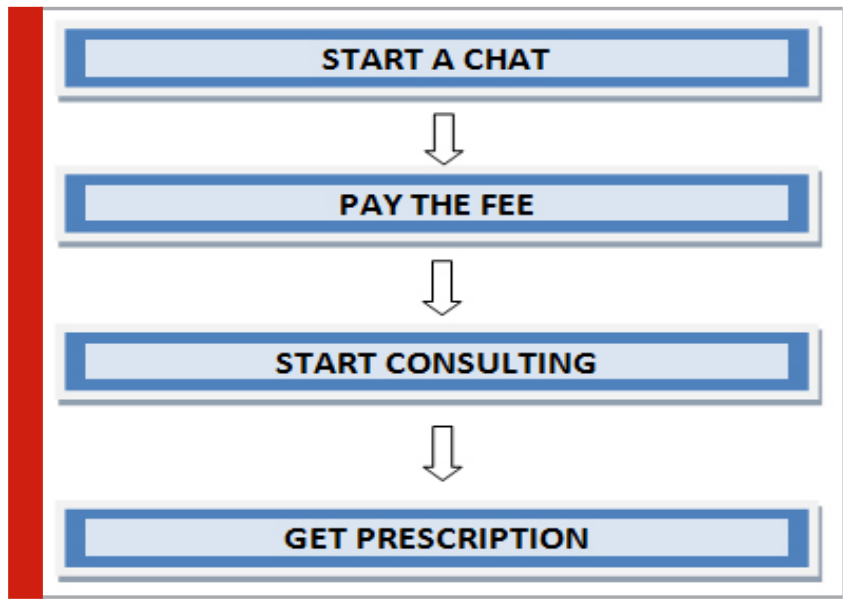

The foremost step for any ailment is to consult a doctor. You can talk to doctor online from the comfort of your home or office and get instant prescription for your health issue other than the extreme emergency issue. In case of extreme emergency, you can consult online doctor consultation team can help in making arrangement for the same.

\section{- Improved ways to check your symptoms}

Figure 2: Checking Symptoms and video consultation

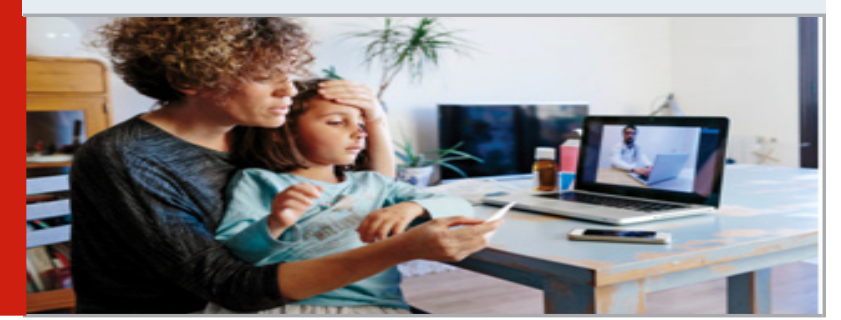

According to reports, number of people who surf on internet about their medical condition is increasing every day. But they just read a blog or watch a video about there symptoms and escape from visiting a doctor and failed in validating about the accuracy of the information they found. While there are situations that still require in-person visits, certain facilities might require or ask patients to have a remote doctor's appointment over a video call to mitigate the risk of COVID-19. The cat is out of bag and it's impossible to stop people from surfing the internet for self-diagnosis. There will always be a limitation on reading a blog or watching a video for self diagnosis. virtual consultation and online doctor could better help in identifying the symptoms and causes (Zodpey, 2018).

\section{- Get Your Prescription}

Figure 3: Online Prescription from Doctor

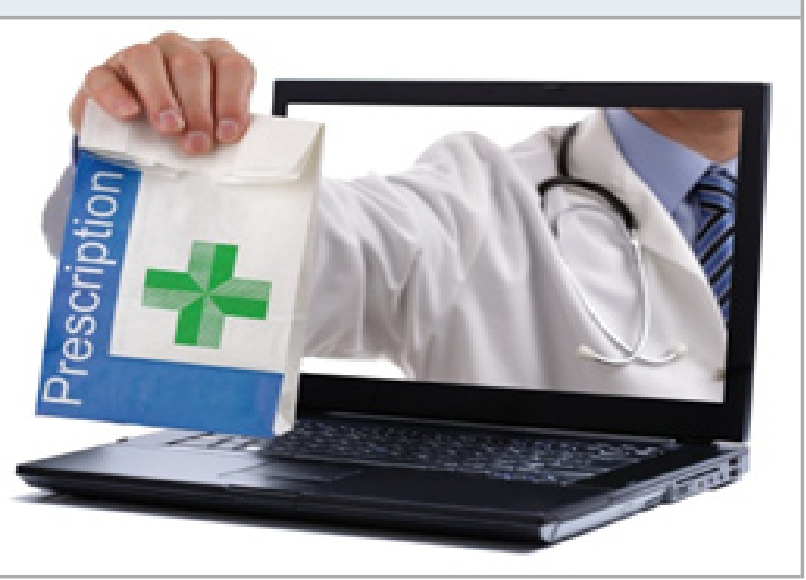

Are you a frequent checker of your health condition and require prescription regularly? You don't need to visit a doctor in hospital to get your prescription. You can however receive the prescription from a nearby pharmacy or directly to your door. But, you might require an doctor examination before you can get your prescription. Medlife, a Bengaluru-based health technology company and online pharmacy, has launched $24 \mathrm{X} 7$ e-consultation services where a patient can teleconsult with 100 general physicians and specialties doctors. However, with just a online consultation with doctor you can get your prescription. Almost, many types of allergy medication and contraceptive can be prescribed by a online doctor.

\section{- Zero risk of infection}

Figure 4: Long queue of patients

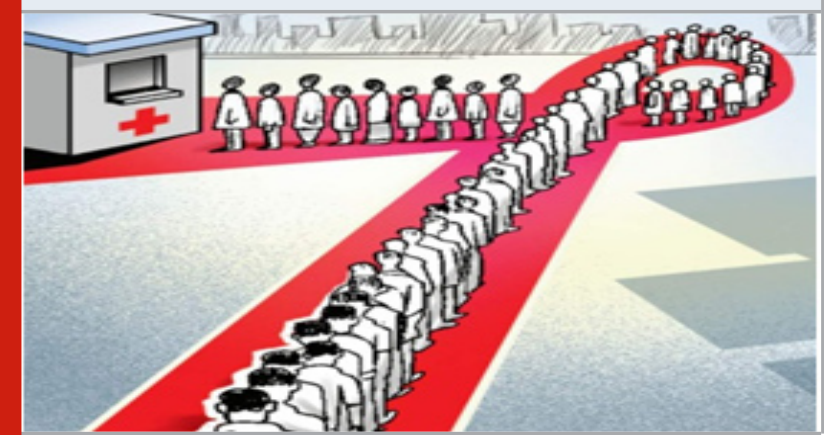


It is extremely risky in visiting the hospital for checkup because it could increase the chance of getting infected by virus. We should always consult a doctor online or offline if you are having any ailment. Consulting online doctor could help you stay away from hospital and clinics as they are especially a hotbed of infections and it's better to stay away from them. With online doctor, there will be a zero risk of getting infected and also you can get a reliable medical care. With long queue there will be a risk of getting infected by virus more. Government hospitals in Hyerabad has already started going digital to keep the patients waiting in a queue for long time (Amrita, 2017). Do wear a mask and keep sanitizer with you and follow social distancing norms when moving out of your home or office.

\section{- Privacy and Security}

Privacy and security is of utmost important when you are communicating anything online. So, it is very important to make sure you are taking consultation from a medical expertise regarding your health condition.

Figure 5: Online consultation security

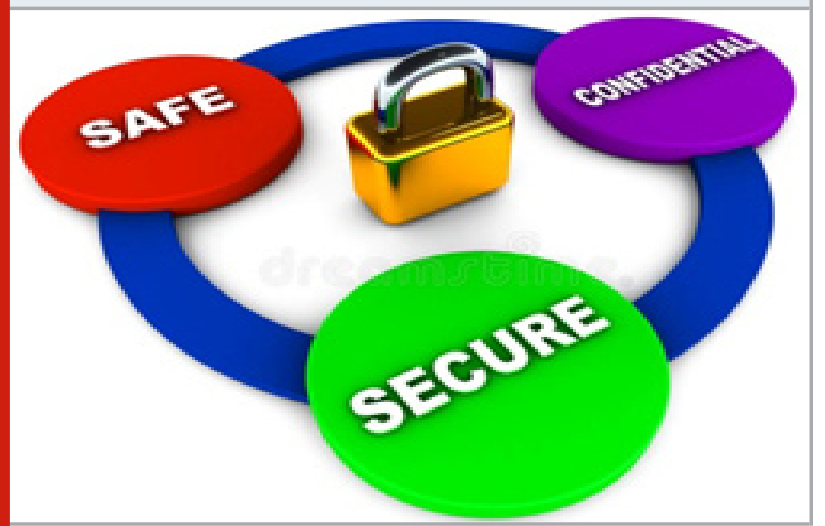

With an online doctor, you can be confident that you are using a secure system and all your information will be totally kept secure and safe (Sawarkar, 2020). However, whatever you are discussing with an online doctor will kept confidential.

Figure 6: 24/7 online consultation services

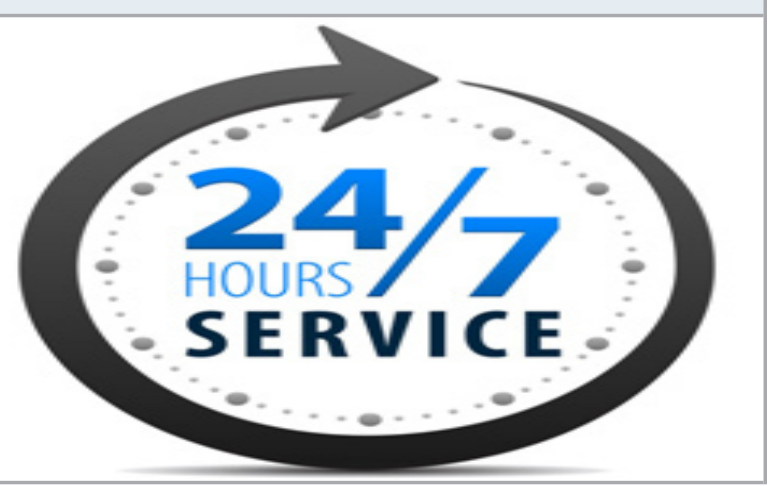

- Comfortable and Convenient

Online consultation is like you can have your health get checked whenever you want it. Consider a following scenario where you woke up in the middle of night with symptoms that you are concerned about-what will you do?

Normally you will rush to a $24 / 7$ hospital or wait for a doctor clinic opens the next day. However, in online consultation you can contact to doctor online 24 hours a day / 7 days a week. without getting bothered to go out in such a terrible time, Get online consultancy from specialist Doctors.

\section{- Get to learn about your own health}

In case of online consultation, sometimes you have to examine yourself. For instance, if you are having a throat infection or a back pain, you need to examine yourself and learn a lot about your health condition.

Figure 7: Self-analysis of health condition

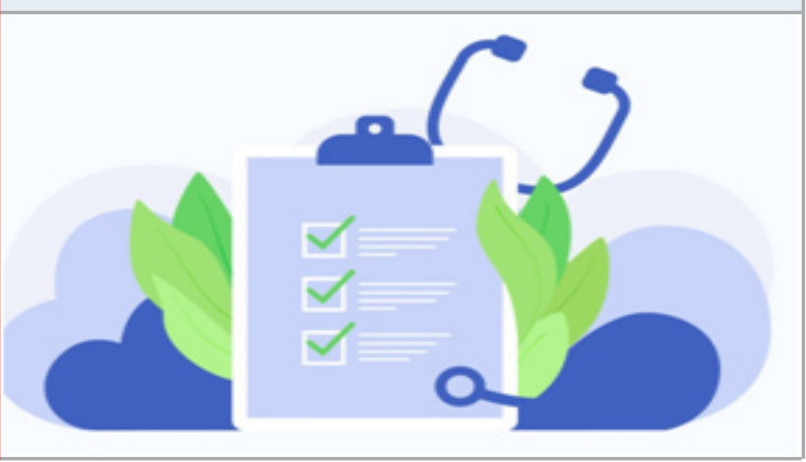

The greater understanding you have regarding your health condition, the better you will be in a position to seek a help from doctor. You need to share pictures or upload a treatment sheet to get better advice from online doctors. You need to be well equipped with BP apparatus, pulse oxymeter, sugar and medical reports.

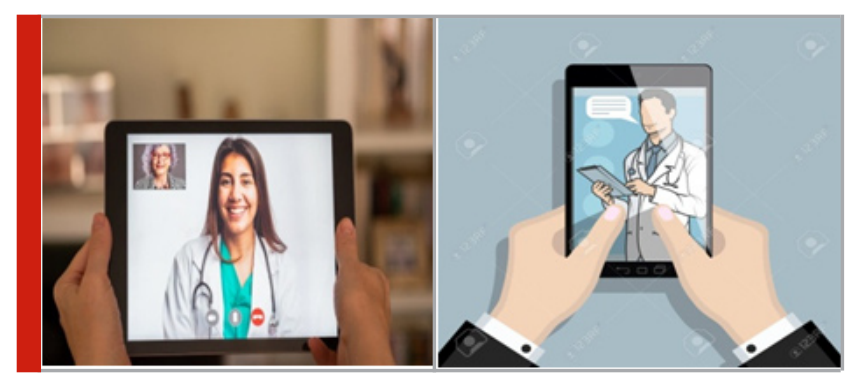

\section{- No travelling required}

When you book an appointment with doctor, for consultation you have to travel a long distance. There will be zero travelling required in case of online doctor consultation. You can just pick up your phone or tablet and send your query online.

You need to just fill the form, send the message, paid the required fee and get prescription for your ailment.

\section{- No waiting time:}

Do you work full-time? Have you got a really busy schedule. You don't need to wait for your turn for 
check-up in online consultation. Get instant help from doctors without any waiting time. Some of the online consultation website details are as follow, else you can alsodo Google search by searching online doctor consultation (Zodpey, 2018).

\section{1. www.apollo247.com}

\section{2.www.tatahealth.com}

\section{3.www.practo.com}

\section{4. www.ahospital.in}

\section{5. www. fortishealthcare.com}

\section{REFERENCES}

Amrita Didyala, 2017. timesofindia.indiatimes.com/ city/hyderabad/government-hospitals-to-go-digitalto-beat-queues/articleshow/61909256.cms.

Kaitlin Miller, 2021. The active times.com/telehealth- coronavirus-virtual-doctor-appointment.

Latchoumi, T.P., Ezhilarasi, T.P. and Balamurugan, K., 2019. Bio-inspired weighed quantum particle swarm optimization and smooth support vector machine ensembles for identification of abnormalities in medical data. SN Applied Sciences, 1(10), pp.1-10.

Sawarkar Gaurav, Punam Sawarkar, and Vaishali Kuchewar, 2020. Ayurveda Students Perception toward Online Learning during the COVID-19 Pandemic. Journal Of Education And Health Promotion 9(1). Canwin, canwinn.org/blog/online-doctor-consultation.

Zodpey Sanjay, Anjali Sharma, ZahiruddinQuazi Syed, Abhay Gaidhane, and SunandaShrikhande, 2018. Allopathic Doctors in India: Estimates, Norms and Projections. Journal of Health Management 20(2): 151-63.

https://ehealth.eletsonline.com/2017/10/medlifelaunches-prescription-based-24x7-free-e-consultationservices/year

https://www.google.com/search?q=online+doctor+cons ultation\&trlz=1C1CHBD_enIN850IN850\&toq=online+do ctor+Ctaqs=chrome. $1.69 \mathrm{i} 5913 \mathrm{j} 69 \mathrm{i} 57 \mathrm{j} 0 \mathrm{i} 402 \mathrm{j} 69 \mathrm{i} 61 \mathrm{j} 69 \mathrm{i} 60 \mathrm{l}$ 2.8399j0j9ctsourceid=chrome\&tie $=U T F-8$. 